\title{
Predicative values of serum microRNA-22 and microRNA-126 levels for non-small cell lung cancer development and metastasis: a case-control study
}

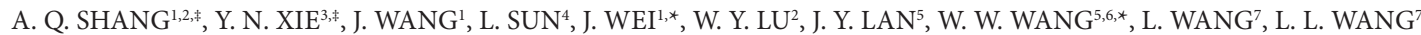

${ }^{1}$ Clinical Medicine School, Ningxia Medical University, Yinchuan 750004, P.R. China; ${ }^{2}$ Department of Laboratory Medicine, The Sixth People's Hospital of Yancheng City, Yancheng 224005, P.R. China; ${ }^{3}$ Department of Laboratory Medicine, The People's Hospital of Jiedong, Jieyang 515500 , P.R. China; ${ }^{4}$ Medicine School, Xiangyang Vocational and Technical College, Xiangyang 441021, P.R. China; ${ }^{5}$ Department of Pathology, The First People's Hospital of Yancheng City, Yancheng 224005, P.R. China; ${ }^{6}$ Department of Pathology, The Sixth People's Hospital of Yancheng City, Yancheng 224005, P.R. China; ${ }^{7}$ Department of Oncology, Chifeng Municipal Hospital of Inner Mongolia Autonomous Region, Chifeng 024000, P.R.China

${ }^{*}$ Correspondence: wangweiwei741@126.com,weijun6321@163.com

${ }^{*}$ Contributed equally to this work.

\section{Received August 2, 2016 / Accepted November 25, 2016}

\begin{abstract}
Presented study aims to explore the predictive values of serum microRNA-22 (miR-22) and miR-126 levels for non-small cell lung cancer (NSCLC) development and metastasis.

A total of 127 NSCLC patients who were admitted in the First People's Hospital of Yancheng City from May, 2013 to May, 2015 were selected as the case group, including 71 cases of adenocarcinoma and 56 cases of squamous cell carcinoma. There were 112 healthy individuals selected as the control group. The qRT-PCR was performed to testify the serum miR-22 and miR-126 levels. Logistic regression analysis was conducted to analyze independent factors influencing NSCLC metastasis and receiver operating characteristic (ROC) curve was drawn to analyze the sensitivity and specificity of serum miR-22 and miR-126 levels in predicting NSCLC developments and metastasis.

The serum miR-22 level was significantly higher in the case group than that in the control group, while the serum miR126 level was lower in the case group as compared with that in the control group. Compared with squamous cell carcinoma patients, serum miR-22 level significantly increased, while serum miR-126 level decreased in patients with adenocarcinoma. Patients at III + IV stage showed increased serum miR-22 level and relatively decreased serum miR-126 level as compared to patients at I + II stage. Serum miR-22 level elevated in patients with metastasis; in contrast serum miR-126 level reduced in comparison to those without metastasis. In patients with familial inheritance, serum miR-22 level increased but serum miR-126 level decreased as compared to those without familial inheritance. The specificity and sensitivity of serum miR-22 and miR-126 levels in predicting NSCLC development were $99.11 \%, 84.30 \%, 82.68 \%$ and $96.40 \%$, respectively. The specificity and sensitivity of serum miR-22 and miR-126 levels in predicting NSCLC metastasis were 59.74\%, 96.00\%, $84.00 \%$ and $62.30 \%$, respectively.

Results indicated that serum miR-22 and miR-126 levels may be used as the predicative biomarkers for NSCLC development and metastasis.
\end{abstract}

Key words: microRNA-22, microRNA-126, non-small cell lung cancer, development, metastasis, predictive value, case-control study

Lung cancer is the major cause of cancer deaths worldwide [1]. Although advances in radio-therapeutics, surgical and chemotherapeutic approaches have been made, the long-term survival rate remains low [2]. Traditionally, decisions on lung cancer therapy have been based on histological considerations, and tumors are assigned to two histological types: non-small cell lung cancer (NSCLC) and small-cell lung cancers [3]. NSCLC comprises three different subtypes: large-cell carci- noma, squamous-cell carcinoma and adenocarcinoma [4]. Tumor extension is one of the major clinical determinants in NSCLC prognosis, which is roughly characterized by the stage [1]. If the cancer is diagnosed at the localized stage, the 5 -year survival rate is about $50 \%$, whereas with lymph node involvement or metastasis, the rate decreases precipitously [5]. It has been suggested that discovery and application of molecular biomarkers together with prognosis signature and 
traditional cancer staging could improve the management of the NSCLC patients [6]. Progress in genomics and proteomics has generated many new biomarkers with potential clinical values, particularly the gene expression profiling by quantitative real-time reverse transcriptase polymerase chain reaction (qRT-PCR) [7, 8]. In recent years, the discovery of microRNAs (miRs) has provided new methods for cancer diagnosis and prediction of treatment response $[9,10]$.

MiRs are a group of naturally occurring small non-coding RNAs that negatively regulate the translation and stability of target protein-coding mRNAs at the 3 ' untranslated region (UTR) [11]. A single miR can regulate a number of downstream genes with different biologic entities, therefore the information obtained from miR profiling could provide more accurate classification of cancer subtypes than expression profiles of protein-coding genes $[10,12]$. The human miR-22 gene is located at a fragile cancer-related genomic region in chromosome 17 (17p13.3), and mapped to an exon of the C17 or f91 gene [13]. MiR-22 is up-regulated in human epithelial cells and senescent fibroblasts but down-regulated in many cancer cell lines and the over-expression of miR-22 induces acquisition of a senescent phenotype and growth suppression in human normal and cancer cells [11]. MiR-126 is located within intron 7 of EGFL7, an epidermal growth factor-domain gene, which is highly expressed in highly vascularized tissues and endothelial cells, and it controls an essential step in vasculogenesis [14]. Furthermore, miR- 126 has been reported to impair tumor progression through signaling pathways related to tumor cell proliferation, invasion, survival and migration [15]. Liu and Lei have found that miR-21 and miR-205 play a role in NSCLC cells' growth, metastasis and sensitivity to radiotherapy and chemotherapy $[16,17]$. However, few studies have been addressed about the effects of serum miR-22 and miR-126 levels on NSCLC development and metastasis. In the present study, predictive values of serum miR-22 and miR-126 levels in NSCLC development and metastasis are discussed in order to provide a novel perspective for the diagnosis and treatment for the NSCLC patients.

\section{Materials and methods}

Ethics statement. The study was approved by the Ethic Committee and was conducted in accordance with the Ethical Principles. The process of blood samples collection completely complied with relevant rules released by the Ethic Committee of the First People's Hospital of Yancheng City, and both the NSCLC patients and healthy individuals signed informed consent at will before the sample collection.

Participants. Altogether 127 NSCLC patients treated in the First People's Hospital of Yancheng City from May, 2013 to May, 2015 were collected in this study as the case group, and all of them were preliminary diagnosed with primary NSCLC according to the cytopathology and histopathology. Among the patients, there were 82 males and 45 females with the mean age of $54.9 \pm 10.8$ years old; according to pathological types, there were 71 cases of adenocarcinoma and 56 cases of squamous cell carcinoma; according to tumor node metastasis (TNM) staging standard released by Union for International Cancer Control (UICC, the $7^{\text {th }}$ version in 2009) [18], 29 of them were at I stage (22.83\%), 21 at II stage (16.54\%), 64 at III stage (50.39\%) and 13 at IV stage (10.24\%); there were 50 patients with metastasis and 77 patients without metastasis. A total of 112 healthy individuals were selected as the control group, including 63 males and 49 females, with the mean age of $44.3 \pm 10.4$ years old. No significant difference of gender and age was found between the control and case groups. The inclusion criteria for NSCLC patients: patients who had not received chemotherapy or radiotherapy; patients without tumor-related disease history; patients diagnosed with NSCLC by postoperative pathological examination. The inclusion criterion for healthy individuals: no tumor-related diseases was found by chest computed tomography $(\mathrm{CT})$, chest X ray, blood test and other general physical tests.

Collection of blood samples and extraction of circulating microRNA. On the second day of admission, whole blood was drawn from all patients. And the drawn blood samples were treated with ethylene diamine tetra-acetic acid (EDTA)K2 anticoagulant and centrifuged to separate plasma, which was dispensed into tubes with $500 \mu \mathrm{l}$ per tube and reserved at $-80^{\circ} \mathrm{C}$ for the later use. A volume of $500 \mu \mathrm{l}$ plasma sample reserved at low temperature was collected and fully mixed with the trizolls (Invitrogen Inc., Carlsbad, CA, USA) which was 3 times the volume of plasma and was melted on ice. Afterwards, the plasma was maintained at room temperature for $15 \mathrm{~min}$ and mixed with $0.5 \mathrm{ml}$ chloroform. Then, the plasma was maintained at room temperature again for $5 \mathrm{~min}$. At $4{ }^{\circ} \mathrm{C}$, the plasma was centrifuged at $14000 \mathrm{r} / \mathrm{min}$ for $15 \mathrm{~min}$ and the upper liquid was transferred into a new tube, after which anhydrous ethanol (1.5 times the volume of the liquid) was poured into the tube. According to the specification of miRNeasy mini kit (TIANGEN Biotechnology Co. Ltd, Beijing, China), RNA was extracted with an adsorbent column. The extracted RNA was dissolved in $500 \mu \mathrm{h} 2 \mathrm{o}$ (RNAase-free). Concentration and purity of the RNA were detected by ultraviolet spectrophotometry and integrity of the RNA was observed by $3 \%$ agarose gel electrophoresis.

Quantitative real-time fluorescent polymerase chain reaction (qRT-PCR). MiR molecular was treated with 3' end poly (A) tract and with reverse transcription according to the specifications of miR reverse transcription cDNA synthesis kit (KR201) (TIANGEN Biotechnology Co. Ltd, Beijing, China). With the synthesized cDNA as the template, qRT-PCR was conducted with taqman $\mathrm{PCR}$ reaction kit provided by Thermo Fisher Scientific (California, USA); besides, miR-16 was regarded as an internal reference (primer sequence was shown in Table 1). Reaction condition was as follows: pre-denatured at $95^{\circ} \mathrm{C}$ for $1 \mathrm{~min}$, denatured at $95^{\circ} \mathrm{C}$ for $15 \mathrm{~s}$, annealed at $60^{\circ} \mathrm{C}$ for $45 \mathrm{~s}$, extended at $72^{\circ} \mathrm{C}$ for $40 \mathrm{~s}$ and 40 cycles in total. In qRT-PCR, repeated and negative controls experiments were conducted, in which each sample was repeated for 3 times in 
quantitative experiment and no cDNA template was added in negative control experiment. The relative expressions of miR22 and miR-126 were shown by $2^{-\Delta \Delta \mathrm{Ct}}$. In each sample, the $\Delta \mathrm{Ct}$ $=\mathrm{Ct}$ targeted gene $-\mathrm{Ct}_{\text {internal reference gene }}$ and $\Delta \Delta \mathrm{CT}=\Delta \mathrm{Ct}$ experiment group $-\Delta \mathrm{C} \mathrm{t}_{\text {control group. }} \mathrm{Ct}$ value represented fluorescence intensity value detected by thermocycler in the reaction. In order to check the integrity of PCR amplification, 3\% agarose gel electrophoresis was used to analyze and verify the specificity of PCR product.

Statistical analysis. SPSS 21.0 software (SPSS Inc.; Chicago, IL, USA) was employed for statistical analysis, in which measurement data was shown by ' $\mathrm{x} \pm \mathrm{s}$ and comparison between two groups was tested by two tail t-test. Logistic regression analysis was adopted to analyze independent factors influencing NSCLC metastasis and ROC curve was used to analyze the sensitivity and specificity of serum miR-22 and miR-126 levels in predicting NSCLC developments and metastasis. $P<0.05$ indicated significant difference.

\section{Results}

Comparison of serum miR-22 and miR-126 levels between the case and control groups. The serum miR-22 level in the case group was significantly higher than that in the
Table 1. PCR primer sequences of microRNA-22, microRNA-126 and microRNA-16.

\begin{tabular}{|c|c|}
\hline Primer & Sequence \\
\hline \multirow{2}{*}{ MicroRNA-22 } & F:5`-GCCTGAAGCTGCCAGTTGA-3’ \\
\hline & R:5`-GTGCAGGGTCCGAGGT-3’ \\
\hline \multirow{2}{*}{ MicroRNA-126 } & F:5`-CGCTGGCGACGGGACATTATTAC-3’ \\
\hline & R:5’-TGCCGTGGACGGCGCATTATTAC-3’' \\
\hline \multirow{2}{*}{ MicroRNA-16 } & F:5`-GCGGATCCAGCACATCATGGTTTACA-3’ \\
\hline & R:5`-GCGTCGACAAAAAATGTTACCTTAAAGGG-3’ \\
\hline
\end{tabular}

PCR, polymerase chain reaction; $F$, forward; $R$, reverse.

control group $(P<0.05)$ (Figure 1$)$; while the serum miR-126 level in the case group was obviously lower than that in the control group $(P<0.05)$.

Comparisons of serum miR-22 and miR-126 levels in the NSCLC patients with different clinical features. There were significant differences of serum miR-22 and miR-126 levels in terms of pathological types, TNM staging, with or without metastasis and with or without familial inheritance (both $P<0.05)$. Compared with squamous cell carcinoma patients, serum miR-22 level significantly increased, while serum miR-

Table 2. Comparisons of serum microRNA-22 and microRNA-126 levels in the NSCLC patients with different clinical features.

\begin{tabular}{|c|c|c|c|c|c|c|c|}
\hline \multirow{2}{*}{ Feature } & \multirow{2}{*}{$\mathrm{N}$} & \multicolumn{3}{|c|}{ MicroRNA-22 } & \multicolumn{3}{|c|}{ MicroRNA -126 } \\
\hline & & Level & $\mathrm{t}$ & $P$ & Level & $\mathrm{t}$ & $P$ \\
\hline \multicolumn{8}{|l|}{ Age (year) } \\
\hline$<60$ & 85 & $1.35 \pm 0.33$ & 0.000 & 0.999 & $0.63 \pm 0.26$ & 0.403 & 0.688 \\
\hline$\geq 60$ & 42 & $1.35 \pm 0.41$ & & & $0.61 \pm 0.27$ & & \\
\hline \multicolumn{8}{|l|}{ Gender } \\
\hline Male & 82 & $1.35 \pm 0.37$ & 0.153 & 0.879 & $0.64 \pm 0.24$ & 0.625 & 0.533 \\
\hline Female & 45 & $1.34 \pm 0.32$ & & & $0.61 \pm 0.29$ & & \\
\hline \multicolumn{8}{|l|}{ Pathologic types } \\
\hline Adenocarcinoma & 71 & $1.40 \pm 0.40$ & 2.085 & 0.039 & $0.57 \pm 0.23$ & 2.652 & 0.009 \\
\hline Squamous cell carcinoma & 56 & $1.27 \pm 0.27$ & & & $0.69 \pm 0.28$ & & \\
\hline \multicolumn{8}{|l|}{ TNM staging } \\
\hline Stage I + II & 50 & $1.10 \pm 0.30$ & 7.679 & $<0.001$ & $0.75 \pm 0.27$ & 4.572 & $<0.001$ \\
\hline Stage III + IV & 77 & $1.51 \pm 0.29$ & & & $0.55 \pm 0.22$ & & \\
\hline \multicolumn{8}{|l|}{ Metastasis } \\
\hline Yes & 50 & $1.52 \pm 0.23$ & 4.847 & $<0.001$ & $0.49 \pm 0.18$ & 5.073 & $<0.001$ \\
\hline No & 77 & $1.23 \pm 0.38$ & & & $0.71 \pm 0.27$ & & \\
\hline \multicolumn{8}{|l|}{ Obstructive pneumonia } \\
\hline Yes & 62 & $1.38 \pm 0.34$ & 0.950 & 0.344 & $0.61 \pm 0.28$ & 0.866 & 0.388 \\
\hline No & 65 & $1.32 \pm 0.37$ & & & $0.65 \pm 0.24$ & & \\
\hline \multicolumn{8}{|l|}{ Familial inheritance } \\
\hline Yes & 15 & $1.75 \pm 0.29$ & 4.031 & $<0.001$ & $0.47 \pm 0.22$ & 3.194 & 0.002 \\
\hline No & 112 & $1.29 \pm 0.33$ & & & $0.66 \pm 0.26$ & & \\
\hline \multicolumn{8}{|l|}{ Smoking history } \\
\hline Yes & 91 & $1.34 \pm 0.32$ & 0.284 & 0.777 & $0.63 \pm 0.26$ & 0.260 & 0.819 \\
\hline No & 36 & $1.36 \pm 0.44$ & & & $0.63 \pm 0.26$ & & \\
\hline
\end{tabular}

NSCLC, non-small cell lung cancer; TNM, tumor node metastasis; N, number; t: Student's $t$-test; $P$, probability; $t$ values and $P$ values were compared between groups. 


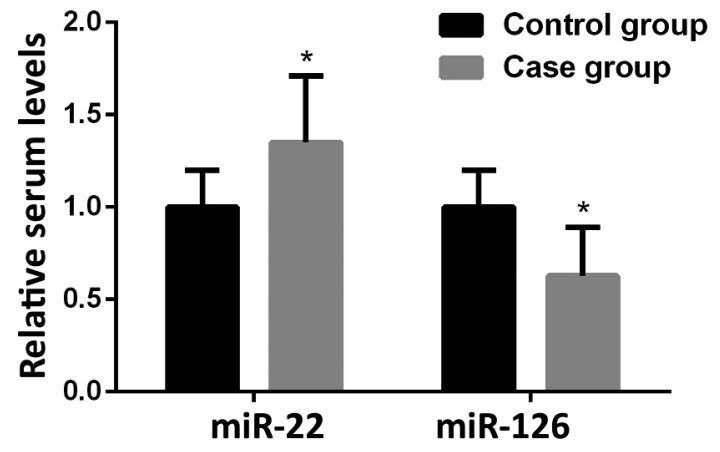

Figure 1. Comparison of serum microRNA-126 and microRNA-22 levels between the case and control groups (' $x \pm s$ ). NSCLC, non-small cell lung cancer; $\mathrm{N}$, number; ${ }^{*}$ compared with the control group, $P<0.05$.

126 level decreased in patients with adenocarcinoma. Patients at III + IV stage showed increased serum miR-22 level and relatively decreased serum miR-126 level as compared to patients at I + II stage. Serum miR-22 level elevated in patients with metastasis; in contrast serum miR-126 level reduced in comparison to those without metastasis. In patients with familial inheritance, serum miR-22 level increased but serum miR-126 level decreased as compared to those without familial inheritance. However, no significant differences were found in age, gender, obstructive pneumonia and smoking history (all $P>0.05$ ) (Table 2).

Logistic regression analysis for independent factors influencing NSCLC metastasis. Single-factor logistic regression analysis of general information of 50 patients with metastasis and 77 patients without metastasis was carried out, including patient's age, gender, smoking history, family inheritance, with or without obstructive pneumonia, pathological types, TNM staging, and serum miR-22 and miR-126 levels. It was indicated that comparisons in term of family inheritance, pathological types, TNM staging and serum miR-22 and miR-126 levels showed significant differences. Postoperative recurrence and metastasis as dependent variable and significant factors of the single-factor analysis as independent variable were included in the multi-factor logistic regression analysis, which illustrated that TNM staging and pathologic types of NSCLC, serum miR-22 and miR-126 levels could be prognostic factors of the NSCLC patients with metastasis (all $P<0.05$ ) (Table 3 ).

ROC curve analysis for serum miR-22 and miR-126 levels in predicating NSCLC development and metastasis. ROC curve was drawn from the comparison of 127 NSCLC patients and 112 healthy participants. The area under the curve (AUC) of serum miR-22 and miR-126 concentrations of were 0.916 (95\%CI: $0.872-0.960, P<0.001)$ and 0.874 (95\%CI: $0.820-0.927, P<0.001)$. The specificity and sensitivity of serum miR-22 and miR-126 levels in NSCLC diagnosis were $99.11 \%$ and $84.30 \%, 82.68 \%$ and $96.40 \%$, respectively at the optimal cutoff value, when relative expression levels of serum miR-22 and miR-126 were 1.07 and 0.95 (Figure 2A, B). ROC curve was drawn based on the comparison of 50 patients with metastasis and 77 patients without metastasis of NSCLC patients. The AUC of miR-22 and miR-126 concentrations were 0.788 (95\%CI: $0.710-0.865)$ and 0.746 (95\%CI: 0.661-0.831). The specificity and sensitivity of serum miR-22 and miR-126 in NSCLC diagnosis were 59.74\% and 96.00\%, $84.00 \%$ and $62.30 \%$ respectively at the optimal cutoff value, when relative levels of serum miR-22 and miR-126 were 1.30 and 0.63 (Figure 2C, D).

\section{Discussion}

Approximately 65\% of NSCLC patients have advanced disease at diagnosis and most NSCLC cases rarely show symptoms and are difficult to be detected, particularly at Stages I and II [19]. Early detection represents a promising strategy to reduce NSCLC mortality [20]. The reference standard in diagnosing NSCLC is pathologic evidence of malignant cells, which typically requires invasive strategies, such as transthoracic needle aspiration, bronchoscopy or thoracotomy [19]. Therefore, it is important to develop new methods and biomarkers with specificity and sensitivity for the detection of NSCLC. In the present study, the serum miR-22 and -126 levels in predicating NSCLC developments and metastasis were analyzed in order to provide a new method for NSCLC diagnosis and treatment.

In the study, the elevated serum miR-22 level was observed in the NSCLC patients. MiR-22, a 22-nt non-coding RNA original-

Table 3. Logistic regression analysis of the independent factors influencing NSCLC metastasis

\begin{tabular}{|c|c|c|c|c|c|c|c|}
\hline \multirow{2}{*}{ Factor } & \multirow{2}{*}{ B } & \multirow{2}{*}{ S.E. } & \multirow{2}{*}{ Wald } & \multirow{2}{*}{ Sig. } & \multirow{2}{*}{$\operatorname{Exp}(B)$} & \multicolumn{2}{|c|}{ 95\%CI for $\operatorname{Exp}(B)$} \\
\hline & & & & & & Lower & Upper \\
\hline Familial inheritance & -2.291 & 0.847 & 7.313 & 0.007 & 0.101 & 0.019 & 0.532 \\
\hline Pathologic types & -2.491 & 0.735 & 11.488 & $<0.001$ & 0.083 & 0.020 & 0.350 \\
\hline TNM staging & -1.913 & 0.865 & 4.889 & 0.027 & 0.148 & 0.027 & 0.805 \\
\hline MicroRNA-22 level & 2.930 & 1.129 & 6.733 & 0.009 & 18.723 & 2.048 & 171.161 \\
\hline MicroRNA-126 level & -3.596 & 1.196 & 9.046 & 0.003 & 0.027 & 0.003 & 0.286 \\
\hline
\end{tabular}

NSCLC, non-small cell lung cancer; TNM, tumor node metastasis; B, partial regression coefficient; S.E., standard error; Sig., significance; Exp(B), exponent function (partial regression coefficient); 95\%CI, 95\% confidence interval. 
A

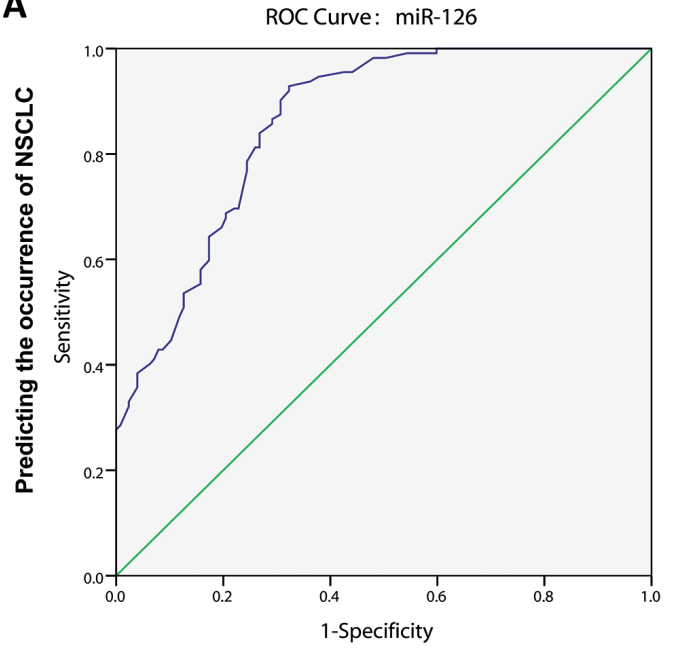

C

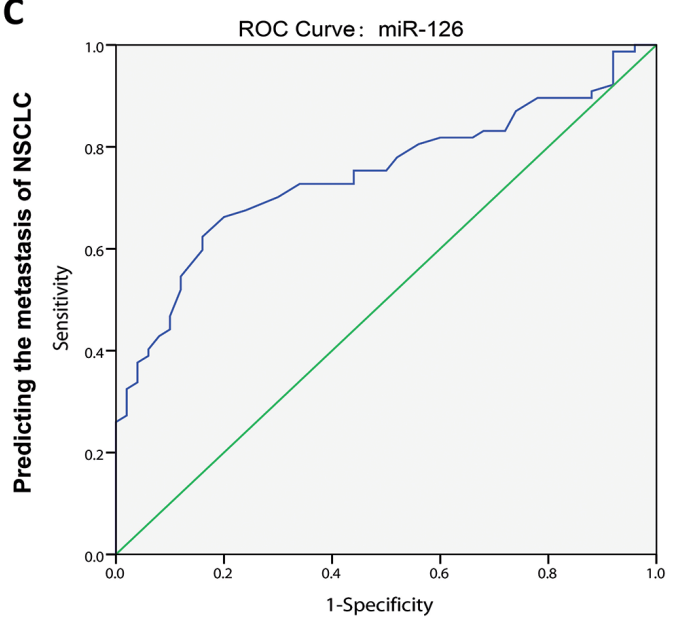

B

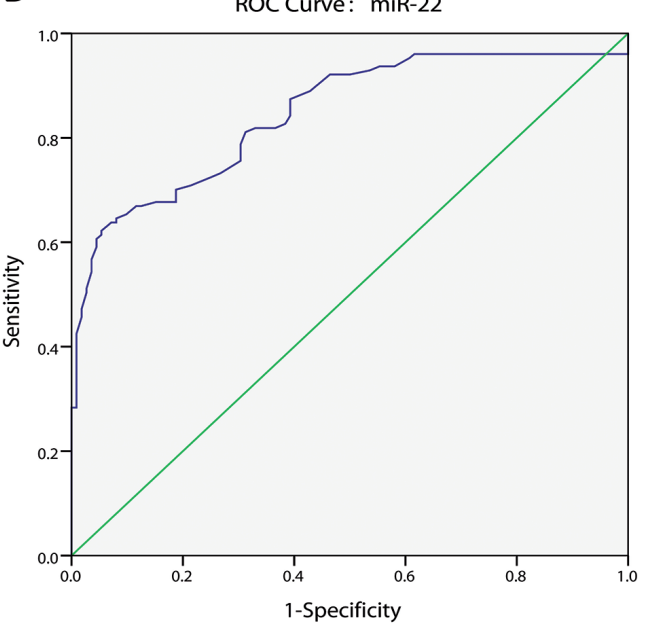

D

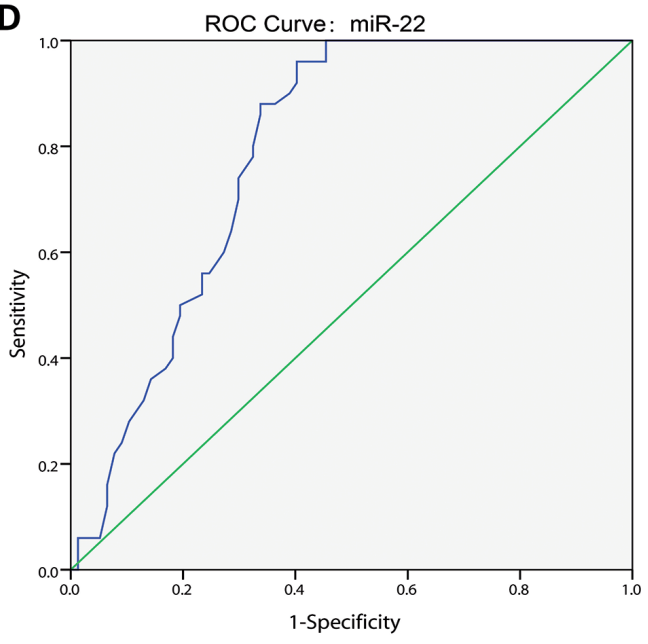

Figure 2. ROC curve analysis for serum microRNA-22 and microRNA-126 levels in predicating NSCLC development and metastasis. A, specificity and sensitivity of serum miR-126 level in predicating NSCLC development; B, specificity and sensitivity of serum miR-22 level in predicating NSCLC development; C, specificity and sensitivity of serum miR-126 level in predicating NSCLC metastasis; D, specificity and sensitivity of serum miR-22 level in predicating NSCLC metastasis.

ly identified in HeLa cells, has been found to be down-regulated in breast cancer, multiple myeloma, cholangiocarcinoma and hepatocellular carcinoma, but over-expressed in prostate cancer [21]. A previous study has suggested that miR-22 functioned in multiple cellular processes, including proliferation, senescence, differentiation and apoptosis, and the deregulation of miR-22 is a hallmark of human cancer [22]. Epithelial to mesenchymal transition (EMT) is a phenotypic manifestation of complex changes in gene expression that include increased expression of mesenchymal markers and decreased expression of epithelial markers [23]. EMT is a key developmental process that cancer cells hijack to increase their invasive potential and aggressiveness [24], and it is mainly characterized by cell-cell adhesion loss, apical-basal cell polarity and the increased motility of cells [25]. In Song's study, it is shown that miR-22 triggers enhanced mammary gland hyperplasia and a marked expansion of the mammary stem cell compartment, hence triggering tumor initiation, and miR-22 promotes the metastatic process and EMT through its ability to repress the expression of $5 \mathrm{hmC}$ as well as miR-200s by directly targeting members of the ten eleven translocation (TET) family [26]. A previous study has shown that NSCLC drug resistance and metastasis has been associated with EMT [27]. Therefore, it is believed that the over-expression of miR-22 has been found in NSCLC which is confirmed by Ling Bo's study in which over-expression of miR-22 was demonstrated in patients with NSCLC [21].

In addition, the study showed NSCLC patients had decreased serum miR-126 level compared with healthy individuals. MiR-126 is an endothelial cell-specific miRNA [28]. Previous reports suggested that miR-126 acts as a tumor suppressor by targeting epidermal growth factor like domain 7 (EGFL7), vascular endothelial growth factor A (VEGF-A) 
or SLC7A5 gene which yields growth advantages $[15,29,30]$. VEGF blockade has a rapid and direct anti-vascular effect in human tumors [31]. EGFL7 expression could promotes tumor progression by down-regulate the expression of endothelial molecules that mediate immune cell infiltration [32]; and SLC7A5 mediates absorption of amino acids, which are used in tumors as oxidative fuel for Adenosine Triphosphate (ATP) production [33]. In addition, Crk, a predicted putative target gene for miR-126, is a member of a family of adaptor proteins that are involved in intracellular signal pathways altering cell adhesion migration and proliferation, and decreased miR-126 in lung cancer cell line results in increased Crk, which is associated with tumor invasion [34]. Consistently, down-regulation of miR-126 in cancerous and noncancerous tissues has been reported for cancers of the lung, cervix, stomach and prostate $[14,35-38]$, by which the result is confirmed.

Finally the study suggested that serum miR-22 and - $126 \mathrm{lev}$ els were significantly different in these clinic features including pathological types, TNM staging, metastasis and family inheritance. And the logistic regression analysis further confirmed that TNM staging, pathological types, and serum miR-22 and miR-126 level may be prognostic factors correlated with foci metastasis of NSCLC patients. Meanwhile, existed study has demonstrated that miR-22 in lung cancer patients could be a useful biomarker in the follow-up of early stage NSCLC and for early diagnosis in healthy heavy smokers [39], and that miR-126 is an independent and strong negative prognostic factor in NSCLC, and its prognostic impact appears related primarily to nodal status and histology [40]. Therefore, serum miR-22 and-126 level may serve as molecular diagnostic and prognostic markers for patients with NSCLC.

In conclusion, the study suggested that biomarker miR22 and -126 were of sensitivity and specificity in predicting NSCLC development and metastasis, thus providing a new method for clinical NSCLC treatment. However, participants collected were patients who were admitted in the First People's Hospital of Yancheng City from May 2013 to May 2015. Thus, the time for follow-up was relatively short and it was unlikely for us to conduct survival analysis. Luckily, we are planning to further our study and add the follow-up in our future research. Nevertheless, the mechanism of correlation between miR-22 and -126 and clinical features of the NSCLC patients remains unknown, and further studies are needed.

Acknowledgments: This study was supported by Immune regulation effect of CD200 induced by microRNA placenta mesenchymal stem cells on acute lung injury (No. 81460247) and 2015 Graduate Education Innovation Program (No. NXYC201511). We are grateful for the contributions and useful suggestions of all the reviewers on our article.

\section{References}

[1] HU Z, CHEN X, ZHAO Y, TIAN T, JIN G et al. Serum microRNA signatures identified in a genome-wide serum
microRNA expression profiling predict survival of non-smallcell lung cancer. J Clin Oncol 2010; 28: 1721-1726. https:// doi.org/10.1200/JCO.2009.24.9342

[2] JEMAL A, SIEGEL R, XU J, WARD E. Cancer statistics, 2010. CA Cancer J Clin 2010; 605: 277-300. https://doi.org/10.3322/ caac. 20073

[3] PAO W, GIRARD N. New driver mutations in non-small-cell lung cancer. Lancet Oncol 2011; 12: 175-180. https://doi. org/10.1016/S1470-2045(10)70087-5

[4] D‘ADDARIO G., Fruh M, Reck M, Baumann P, KLEPETKO W et al. Metastatic non-small-cell lung cancer: ESMO Clinical Practice Guidelines for diagnosis, treatment and follow-up. Ann Oncol 2010; 21 Suppl 5: v116-119. https:// doi.org/10.1093/annonc/mdq189

[5] HU Z, CHEN J, TIAN T, ZHOU X, GU H et al. Genetic variants of miRNA sequences and non-small cell lung cancer survival. J Clin Invest 2008; 118: 2600-2608. https://doi. org/10.1172/jci34934

[6] LUDWIG JA, WEINSTEIN JN. Biomarkers in cancer staging, prognosis and treatment selection. Nat Rev Cancer 2005; 5: 845-856. https://doi.org/10.1038/nrc1739

[7] CHEN HY, YU SL, CHEN CH, CHANG GC, CHEN CY et al. A five-gene signature and clinical outcome in non-smallcell lung cancer. N Engl J Med 2007; 356: 11-20. https://doi. org/10.1056/NEJMoa060096

[8] TSAO MS, SAKURADA A, CUTZ JC, ZHU CQ, KAMELREID $S$ et al. Erlotinib in lung cancer - molecular and clinical predictors of outcome. N Engl J Med 2005; 353: 133-144. https://doi.org/10.1056/NEJMoa050736

[9] ESQUELA-KERSCHER A, SLACK FJ. Oncomirs - microRNAs with a role in cancer. Nat Rev Cancer 2006; 6: 259-269. https://doi.org/10.1038/nrc1840

[10] CALIN GA, CROCE CM. MicroRNA signatures in human cancers. Nat Rev Cancer 2006; 6: 857-866. https://doi. org/10.1038/nrc1997

[11] XU D, TAKESHITA F, HINO Y, FUKUNAGA S, KUDO Y et al. miR-22 represses cancer progression by inducing cellular senescence. J Cell Biol 2011; 193: 409-424. https://doi. org $/ 10.1083 /$ jcb. 201010100

[12] LU J, GETZ G, MISKA EA, ALVAREZ-SAAVEDRA E, LAMB J et al. MicroRNA expression profiles classify human cancers. Nature 2005; 435: 834-838. https://doi.org/10.1038/ nature 03702

[13] XIONG J, YU D, WEI N, FU H, CAI T et al. An estrogen receptor alpha suppressor, microRNA-22, is downregulated in estrogen receptor alpha-positive human breast cancer cell lines and clinical samples. FEBS J 2010; 277: 1684-1694. https:// doi.org/10.1111/j.1742-4658.2010.07594.X

[14] SAITO Y, FRIEDMAN JM, CHIHARA Y, EGGER G, CHUANG JC et al. Epigenetic therapy upregulates the tumor suppressor microRNA-126 and its host gene EGFL7 in human cancer cells. Biochem Biophys Res Commun 2009; 379: 726-731. https://doi.org/10.1016/j.bbrc.2008.12.098

[15] SUN Y, BAI Y, ZHANG F, WANG Y, GUO Y et al. miR-126 inhibits non-small cell lung cancer cells proliferation by targeting EGFL7. Biochem Biophys Res Commun 2010; 391: 1483-1489. https://doi.org/10.1016/j.bbrc.2009.12.098 
[16] LIU ZL, WANG H, LIU J, WANG ZX. MicroRNA-21 (miR21) expression promotes growth, metastasis, and chemo- or radioresistance in non-small cell lung cancer cells by targeting PTEN. Mol Cell Biochem 2013; 372: 35-45. https://doi. org/10.1007/s11010-012-1443-3

[17] LEI L, HUANG Y, GONG W. miR-205 promotes the growth, metastasis and chemoresistance of NSCLC cells by targeting PTEN. Oncol Rep 2013; 30: 2897-2902.

[18] YOSHIDA Y, MURAYAMA T, SATO Y, SUZUKI Y, SAITO $\mathrm{H}$ et al. Validation of 7 th TNM staging system for lung cancer, based on surgical outcomes. Asian Cardiovasc Thorac Ann 2013; 21: 693-699. https://doi. org $/ 10.1177 / 0218492312470670$

[19] CHEN X, HU Z, WANG W, BA Y, MA L et al. Identification of ten serum microRNAs from a genome-wide serum microRNA expression profile as novel noninvasive biomarkers for nonsmall cell lung cancer diagnosis. Int J Cancer 2012; 130: 1620-1628. https://doi.org/10.1002/ijc.26177

[20] ULIVI P, MERCATALI L, CASONI GL, SCARPI E, BUC$\mathrm{CHI} \mathrm{L}$ et al. Multiple marker detection in peripheral blood for NSCLC diagnosis. PLoS One 2013; 8: e57401. https://doi. org/10.1371/journal.pone.0057401

[21] LING B, WANG GX, LONG G, QIU JH, HU ZL. Tumor suppressor miR-22 suppresses lung cancer cell progression through post-transcriptional regulation of ErbB3. J Cancer Res Clin Oncol 2012; 138: 1355-1361. https://doi.org/10.1007/ s00432-012-1194-2

[22] ZUO QF, CAO LY, YU T, GONG L, WANG LN et al. MicroRNA-22 inhibits tumor growth and metastasis in gastric cancer by directly targeting MMP14 and Snail. Cell Death Dis 2015; 6: e2000. https://doi.org/10.1038/cddis.2015.297

[23] THOMSON S, PETTI F, SUJKA-KWOK I, MERCADO P, BEAN J et al. A systems view of epithelial-mesenchymal transition signaling states. Clin Exp Metastasis 2011; 28: 137-155. https://doi.org/10.1007/s10585-010-9367-3

[24] NIETO MA. The ins and outs of the epithelial to mesenchymal transition in health and disease. Annu Rev Cell Dev Biol 2011; 27: 347-376. https://doi.org/10.1146/annurevcellbio-092910-154036

[25] YILMAZ M, CHRISTOFORI G. EMT, the cytoskeleton, and cancer cell invasion. Cancer Metastasis Rev 2009; 28: 15-33. https://doi.org/10.1007/s10555-008-9169-0

[26] SONG SJ, POLISENO L, SONG MS, ALA U, WEBSTER K et al. MicroRNA-antagonism regulates breast cancer stemness and metastasis via TET-family-dependent chromatin remodeling. Cell 2013; 154: 311-324. https://doi.org/10.1016/j. cell.2013.06.026

[27] NEEL DS, BIVONA TG. Secrets of drug resistance in NSCLC exposed by new molecular definition of EMT. Clin Cancer Res 2013; 19: 3-5. https://doi.org/10.1158/1078-0432.CCR-12-3232

[28] CHEN JJ, ZHOU SH. Mesenchymal stem cells overexpressing MiR-126 enhance ischemic angiogenesis via the AKT/ ERK-related pathway. Cardiol J 2011; 18: 675-681. https:// doi.org/10.5603/CJ.2011.0032
[29] LIU B, PENG XC, ZHENG XL, WANG J, QIN YW. MiR-126 restoration down-regulate VEGF and inhibit the growth of lung cancer cell lines in vitro and in vivo. Lung Cancer 2009; 66: 169-175. https://doi.org/10.1016/j.lungcan.2009.01.010

[30] MIKO E, MARGITAI Z, CZIMMERER Z, VARKONYI I, DEZSO B et al. miR-126 inhibits proliferation of small cell lung cancer cells by targeting SLC7A5. FEBS Lett 2011; 585: 1191-1196. https://doi.org/10.1016/j.febslet.2011.03.039

[31] WILLETT CG, BOUCHER Y, DI TOMASO E, DUDA DG, MUNN LL et al. Direct evidence that the VEGF-specific antibody bevacizumab has antivascular effects in human rectal cancer. Nat Med 2004; 10: 145-147. https://doi.org/10.1038/ $\underline{\mathrm{nm} 988}$

[32] DELFORTRIE S, PINTE S, MATTOT V, SAMSON C, VILLAIN G et al. Egfl7 promotes tumor escape from immunity by repressing endothelial cell activation. Cancer Res 2011; 71: 7176-7186. https://doi.org/10.1158/0008-5472.CAN-11-1301

[33] GALLUCCIO M, PINGITORE P, SCALISE M, INDIVERI C. Cloning, large scale over-expression in E. coli and purification of the components of the human LAT 1 (SLC7A5) amino acid transporter. Protein J 2013; 32: 442-448. https://doi. org/10.1007/s10930-013-9503-4

[34] CRAWFORD M, BRAWNER E, BATTE K, YU L, HUNTER MG et al. MicroRNA-126 inhibits invasion in non-small cell lung carcinoma cell lines. Biochem Biophys Res Commun 2008; 373: 607-612. https://doi.org/10.1016/j. bbrc.2008.06.090

[35] YANAIHARA, N., CAPLEN N, BOWMAN E, SEIKE M, KUMAMOTO K et al. Unique microRNA molecular profiles in lung cancer diagnosis and prognosis. Cancer Cell 2006; 9: 189-198. https://doi.org/10.1016/j.ccr.2006.01.025

[36] CHO WC, CHOW AS, AU JS. Restoration of tumour suppressor hsa-miR-145 inhibits cancer cell growth in lung adenocarcinoma patients with epidermal growth factor receptor mutation. Eur J Cancer 2009; 45: 2197-2206. https://doi. org/10.1016/j.ejca.2009.04.039

[37] WANG X, TANG S, LE SY, LU R, RADER JS et al. Aberrant expression of oncogenic and tumor-suppressive microRNAs in cervical cancer is required for cancer cell growth. PLoS One 2008; 3: e2557. https://doi.org/10.1371/journal. pone.0002557

[38] FENG R, CHEN X, YU Y, SU L, YU B et al. miR-126 functions as a tumour suppressor in human gastric cancer. Cancer Lett 2010; 298: 50-63. https://doi.org/10.1016/j.canlet.2010.06.004

[39] FRANCHINA T, AMODEO V, BRONTE G, SAVIO G, RICCIARDI GR et al. Circulating miR-22, miR-24 and miR-34a as novel predictive biomarkers to pemetrexed-based chemotherapy in advanced non-small cell lung cancer. J Cell Physiol 2014; 229: 97-99.

[40] DONNEM T, LONVIK K, EKLO K, BERG T, SORBYE SW et al. Independent and tissue-specific prognostic impact of miR126 in nonsmall cell lung cancer: coexpression with vascular endothelial growth factor-A predicts poor survival. Cancer 2011; 117: 3193-3200. https://doi.org/10.1002/cncr.25907 